\title{
Serotyping of Escherichia coli isolated from piglet diarrhea
}

\author{
M. Regon, D. C. Pathak, S. M. Tamuli and G. K. Baruah \\ Department of Pathology, College of Veterinary Science, Assam Agricultural University, Khanapara, Guwahati - 781022, \\ Assam, India. \\ Corresponding author: Monjula Regon, email: manjularegon@gmail.com, DCP: dcpathak@gmail.com, \\ SMT: tamuli_sm@yahoo.com, GKB: gkbaruah53@gmail.com \\ Received: 11-05-2014, Revised: 11-07-2014, Accepted: 16-07-2014, Published online: 21-08-2014
}

doi: 10.14202/vetworld.2014.614-616. How to cite this article: Regon M, Pathak DC, Tamuli SM, Baruah GK (2014)

Serotyping of Escherichia coli isolated from piglet diarrhoea, Veterinary World 7(8):614-616.

\begin{abstract}
Aim: The aim was to investigate the different strains of Escherichia coli isolated from diarrheic piglets by serological typing.

Materials and Methods: A total of 150 isolates consists of 66 from diarrheic feces and 84 from intestinal contents were subjected to serological typing. The isolates were referred to National Salmonella and E. coli Center, CRI, Kasauli, Himachal Pradesh, India for serotyping.

Result: Of 150 isolates, 90 isolates were serotyped into 20 different serogroups, 4 isolates were rough and remaining 56 isolates were refractory to serotype. The most frequently encountered serogroups were O76 (25 strains), O60 (18 strains), O120 (11 strains), O87 (6 strains), O107 and O80 (5 strains each), O84 and O64 (3 strains each), and O117 and O158 (2 strains each). The other serogroups identified were O3, 05, O24, O25, O36, O42, O100, O116, 0132, and O140 (1 strain each), 3 rough and 56 strains were untypable.
\end{abstract}

Conclusion: The results in the present study showed that variable strains of $E$. coli are responsible for diarrhea in piglets.

Keywords: diarrhea, Escherichia coli, piglet, serotype.

\section{I ntroduction}

Gastrointestinal disorders in pigs are a great economic challenge to intensive pig farming. They cause substantial economic losses due to mortality, stunted growth, and prolonged time for reaching slaughter weight [1]. Pathogenic Escherichia coli is a common agent responsible for a variety of intestinal disorders. Porcine neonatal diarrhea and post weaning diarrhea caused by enterotoxigenic E. coli (ETEC) result in significant mortality and morbidity, and are economically important diseases of pigs [2].

Secretory diarrhea is associated with ETEC infection and is mediated by any one of the several enterotoxin including heat-labile enterotoxin, heat stable enterotoxin-a, and heat stable enterotoxin-b [3]. The ETEC colonization in the small intestine is mediated by fimbriae that attach to the receptors on the villous enterocytes [4]. Fimbriae including K88 (F4), K99 (F5), 987P (F6), F18, and F41 are commonly found and porcine $E$. coli strains expressing these fimbriae are clinically important for porcine diarrhea [5,6]. Certain serotypes of $E$. coli are far more likely to be associated with some of the virulence factor of diarrheagenic $E$. coli than other serotypes.

The purpose of the present study was to find out the frequency of different serotypes among diarrheal cases in piglets below 2 months of age.

Copyright: The authors. This article is an open access article licensed under the terms of the Creative Commons Attributin License (http:// creative commons.org/licenses/by/2.0) which permits unrestricted use, distribution and reproduction in any medium, provided the work is properly cited.

\section{Materials and Methods}

\section{Ethical approval}

Collection of samples was done as per standard procedure.

\section{Collection of samples}

The samples were collected from piglets below 2 months of age with the history of diarrhea viz. yellowish watery feces with the offensive smell, dehydration, and weakness. Rectal swabs were collected aseptically and diluted in phosphate buffered saline and preserved in the refrigerator until used. Then the intestinal contents from dead piglets were also collected aseptically and preserved in the refrigerator until used. Piglets died of diarrhea revealed typical lesions of gastroenteritis viz. stomachs contained undigested material, watery to blood mixed fluid in the intestine and mild catarrhal enteritis to severe hemorrhagic gastroenteritis.

\section{I solation and identification of E. coli}

The rectal swabs and intestinal contents were inoculated into MacConkey's lactose agar for primary isolation by streak plate following a standard protocol [7]. Pink-colored colonies representing coliforms were picked and subcultured in eosin methylene blue agar plates for purification of the isolates. Characterization and identification of the organisms were made by a standard protocol described earlier [8] on the basis of the criteria viz. colony morphology, morphological characteristics in Gram's staining, and biochemical characteristics. 


\section{Serotyping of E. coli}

The purified colonies were subcultured into nutrient agar slants and preserved at $4^{\circ} \mathrm{C}$. The duplicate cultures were referred to National Salmonella and Escherichia coli Research center, Kasauli, Himachal Pradesh for serological typing.

\section{Results}

Of 150 isolates consisted of 66 from diarrheic feces and 84 from intestinal contents, were subjected to serological typing. Altogether 90 (60\%) isolates could be serotyped into 20 different serogroups, $4(2.6 \%)$ isolates were rough and remaining 56 (37.33\%) isolates were refractory to serotype as shown in Table-1. The most frequently encountered serogroups were O76 (25 strains), followed by O60 (18 strains), O120 (11 strains), O87 (6 strains), $\mathrm{O} 107$ and $\mathrm{O} 80$ (5 strains each), $\mathrm{O} 84$ and $\mathrm{O64}$ (3 strains each), and $\mathrm{O} 117$ and $\mathrm{O} 158$ (2 strains each). The other serogroups identified were $\mathrm{O} 3,05, \mathrm{O} 24, \mathrm{O} 25, \mathrm{O} 36$, O42, O100, O116, 0132, and O140 (1 strain each).

However, of 66 isolates from diarrheic feces, 44 (66.66\%) isolates could be serotyped into 16 different serogroups, 3 isolates were rough and 19 isolates were refractory to serotype. The serogroups identified were O76 (12 strains), O60 (8 strains), O120 (4 strains), O64 (3 strains), O117, O158, O84 and O80 (2 strains each), O140, O5, O3, O24, O87, O100, O25 O36, and O116 (1 strain each). Of 84 isolates from intestinal contents, 46 (54.76\%) isolates could be serotyped into 9 different serogroups, one rough and 37 isolates were refractory to serotype. The serogroups identified were

Table-1: Different serogroups of E. coli isolated from diarrheic piglets.

\begin{tabular}{|c|c|c|c|}
\hline Serogroup & $\begin{array}{l}\text { Strain of } \\
\text { E. coli from } \\
\text { diarrheic } \\
\text { feces }\end{array}$ & $\begin{array}{c}\text { Strain of } \\
\text { E. coli from } \\
\text { intestinal } \\
\text { contents }\end{array}$ & $\begin{array}{c}\text { Total } \\
\text { number } \\
\text { of strains }\end{array}$ \\
\hline 03 & 1 & - & 1 \\
\hline O5 & 1 & - & 1 \\
\hline $\mathrm{O} 24$ & 1 & - & 1 \\
\hline $\mathrm{O} 25$ & 1 & - & 1 \\
\hline 036 & 1 & - & 1 \\
\hline 042 & - & 1 & 1 \\
\hline 060 & 8 & 10 & 18 \\
\hline 064 & 3 & - & 3 \\
\hline 076 & 12 & 13 & 25 \\
\hline 080 & 2 & 3 & 5 \\
\hline 084 & 2 & 1 & 3 \\
\hline 087 & 1 & 5 & 6 \\
\hline 0100 & 1 & - & 1 \\
\hline 0107 & - & 5 & 5 \\
\hline 0116 & 1 & - & 1 \\
\hline 0117 & 2 & - & 2 \\
\hline 0120 & 4 & 7 & 11 \\
\hline 0132 & - & 1 & 1 \\
\hline 0140 & 1 & - & 1 \\
\hline 0158 & 2 & - & 2 \\
\hline Rough & 3 & 1 & 4 \\
\hline Untypable & 19 & 37 & 56 \\
\hline Total & 66 & 84 & 150 \\
\hline
\end{tabular}

E. coli $=$ Escherichia coli
O76 (13 strains), O60 (10 strains), O120 (7 strains), O87 and 0107 (5 strains each), O80 (3 strains), O42, O84, and 0132 (1 strain each). Another 3 strains were identified to be rough and 56 strains were refractory to serotyping.

\section{Discussion}

Diarrhea is the most common cause of neonatal mortality in pigs in India, particularly in the North Eastern states. In the present study, 90 isolates were serotyped into 20 different serogroups. The most frequently encountered serogroups were O76 (25 strains), O60 (18 strains), O120 (11 strains), O87 (6 strains), O107 and O80 (5 strains each), O84 and $\mathrm{O} 64$ ( 3 strains each), and $\mathrm{O} 117$ and $\mathrm{O} 158$ (2 strains each), O3, O5, O24, O25, O36, O42, O100, O116, O132, and O140 (1 strain each). Although a variety of serogroups has been associated with diarrhea, a limited number of serogroups has been reported in enteric infections of piglets [9].

The common serogroups of E. coli observed in the present study and recorded earlier by different workers from different parts of the world were O5, O24, O25, O76, O120, O80, O84, O100, O116 [10-12]. The other serogroups O60, O100, O116, O117, and O120 were reported from diarrheic piglets in Korea [13]. Serogroup O80 has been reported from $23.56 \%$ of $E$. coli strains isolated from diarrheic piglets in Western China [14]. No reports have been found regarding prevalence of serotype viz. O3, O36, O42, O64, O84, O87, O132, O140, and 0158 . Thus, further characterization of their virulence factors is the most important. Moreover, there are certain serotypes which were refractory to serotyping, and they are also important for detection of their virulence factors.

The frequencies of serogroups could vary from area to area and over time to time $[15,16]$. Moreover, the virulence genes in E. coli vary with the geographical area [17].

\section{Conclusion}

The results indicate that the regional difference or other selective advantages may result in E. coli strains with certain O- serogroups adapting to survival in the swine intestine and their environment. Hence, variable serogroups of $E$. coli are associated with diarrhea in piglets causing mortality in young pigs causing heavy economic losses to pig industry. The results provide preliminary information about the various serotypes of $E$. coli responsible for diarrhea in piglets in around organized farms of Guwahati, Assam and constitute an important database for the implementation of prevention, diagnosis, and treatment measures.

\section{Authors' Contributions}

MR collected samples for the present study. Rest of the authors equally contributed in the preparation of 
the manuscript. All the authors read and approved for the final manuscript.

\section{Acknowledgments}

The authors extend their sincere thanks to the Dean, Faculty of Veterinary Science and the Director, Post Graduate Studies, Assam Agricultural University for providing necessary facilities and fund to conduct the present study. The authors are also thankful to the Director, National Salmonella and Escherichia Institute, Central Research Institute, Kasauli, H.P. India for Serotyping of E. coli isolates.

\section{Competing I nterests}

The authors declare that they have no competing interests.

\section{References}

1. Moxley, R.A. and Duhamel, G.E. (1999) Comparative pathology of bacterial enteric diseases of swine. Adv. Exp. Med. Biol., 473: 83-101.

2. Zhang, W., Berberrow, E.M., Freeling, J., He, D., Morley, R.A. and Francis, D.H. (2006) Significance of heat labile and heat stable enterotoxins in porcine colibacillosis in an additive model for pathogenecity study. Infect. Immun., 74(6): 3107-3114.

3. Fleckenstein, J.M., Hardwidge, P.R., Munson, G.P., Rasko, D.A., Sommefelt, H. and Steinsland, H. (2010) Molecular mechanism of enterotoxigenic Escherichia coli infection. Microbes. Infect., 12: 89-98.

4. Madoroba, E., van Driessche, E., De Greve, H., Mast, J., Ncube, I., Read, J. and Beeckmans, S. (2009) Prevalence of enterotoxigenic Escherichia coli virulence gene from scouring piglets in Zimbabew. Trop. Anim. Health Prod., 41: 1539-1547.

5. Vu-Khac, H., Holoda, E., Pilipcinec, E., Blanco, M., Blanco, J.E., Dahbi, G., Mora, A., Lopez, C., Gonzalez, E.A. and Blanco, J. (2007) Serotypes, virulence genes, intimin types and PFGE profiles of Escherichia coli isolated from piglets with diarrhoea in Slovakia. Vet. J., 174(1): 176-187.

6. Kim, Y.J., Kim, J.H., Hur, J. and Le, J.H. (2010) Isolation of Escherichia coli from piglets in South Korea with diarrhoea and characteristics of the virulence genes. Can. J. Vet. Res., 74(1): 59-64.
7. Collins, C.H. and Lyne, P.M. (1970) Microbiological Methods. Laboratory technique series. University Park Press, Baltimore, London.

8. Cruickshank, R., Duguid, J.P., Marimion, B.P. and Swain, R.H.A. (1975). Medical Microbiology. $12^{\text {th }}$ ed., Vol. II. Churchill Livingstone, Edinburgh, London and New York.

9. Frydendahl, K. (2002) Prevalence of serogroups and virulence genes in Escherichia coli associated with postweaning diarrhoea and edema disease in pigs and a comparison of diagnostic diagnostic approaches. Vet. Microbiol., 85: $169-182$.

10. Chen, X., Gao, S., Jiao, X. and Liu, X.F. (2004) Prevalence of serogroups and virulence factors of Escherichia coli strains isolated from pigs with postweaning diarrhoea in eastern China. Vet. Microbiol., 103(1-2): 13-20.

11. Roychoudhury, P., Saikia, G.K and Rahman, H. (2002) Serotyping antibiogram of Escherichia coli isolated from diarrhoeic piglets. Indian J. Anim. Sci., 74(1): 41-42.

12. Fratamico Pina, M., Bagi Lori, K., Bush Eric, J. and Barbara, T. (2004) Prevalence and characterization of shiga toxin-producing Escherichia coli in swine faeces recovered in the National Animal Health Monitoring System's Swine 2000 Study. Appl. Env. Microbiol., 70(12): 7173-7178.

13. Byun, J.W., Jung, B.Y., Kim, H.Y., Fairbrother, J.M. Lee, R.M.H. and Lee, W.K. (2013) O-serogroups, virulence genes of pathogenic Escherichia coli and Pulsed-field gel electrophoresis (PFGE) patterns of O149 isolates from diarrhoeic piglets in Korea. Vet. Med., 58(9): 468-476.

14. Xuefeng, Q., Huang, N., Zhao, B., Chungjiang, W. and Zhao, X. (2012) Prevalence of serogropus and genotypes for fimbriae and enterotoxin in Escherichia coli isolated from diarrhoeic piglet in Western China. J. Swine Health Prod., 20(6): 290-293.

15. Harel, J., Lapointe, H., Fallara, A., Lortie, L.A., BigrasPoulin, M., Lariviere, S. and Fairbrother, J.M. (1991) Detection of genes for fimbrial antigens and enterotoxins associated with Escherichia coli serogroups isolated from pigs with diarrhoea. J. Clin. Microbiol., 29(4): 745-752.

16. Fairbrother, J.M., Nadeau, E. and Gyles, C.L. (2005) Escherichia coli in postweaning diarrhoea in pigs: An update on bacterial types, pathogenesis, and prevention strategies. Anim. Health Res. Rev., 6: 17-39.

17. Andrea, T., Daniela, G., Celene, C., Rosalba, C., Jorge, L., Silvia, G. and Ana Marı, C. (2012) Prevalence of virulence genes in Escherichia coli strains isolated from piglets in the suckling and weaning period in Mexico. J Med. Microbiol. 61(Pt 1): 148-156. 